\title{
Los manglares de México: una revisión
}

\author{
Jorge López Portillo ${ }^{1}$ \\ Exequiel Ezcurra ${ }^{2}$
}

\begin{abstract}
RESUMEN
En este trabajo se revisó la información bibliográfica existente sobre los manglares de México. El primer tema analizado es la biogeografía, describiendo la diversidad y composición de los manglares de las dos costas del país, así como los límites de su distribución. La distribución, composición y fisonomía de las comunidades de manglar están influidas por los cambios latitudinales en la temperatura y la precipitación, pero localmente dependen de la geomorfología, el substrato, la salinidad, la inundación y el relieve. Los estudios al presente sugieren que las interacciones bióticas también pueden influir en los patrones de zonación observados y que los óptimos fisiológicos y ecológicos de las especies no siempre coinciden espacialmente. La caída de hojarasca se ha estudiado en las costas del Golfo de México y del Océano Pacífico. También se analizaron trabajos sobre descomposición de hojarasca y su dinámica, de fenología y las estimaciones de deforestación, la que al parecer es de $5 \%$ anual. Se hace un análisis de las fuentes de perturbación, como la construcción de infraestructura turística, camaronicultura y sustitución por campos de cultivo y potreros, las actividades industriales y los errores derivados del cambio de la dinámica hidrológica de estuarios completos. La conclusión es que los retos son muy grandes y es necesaria una mayor cantidad de estudios sobre la biología, ciclos de vida, valuación y manejo, distribución y formas de drenaje de los manglares.
\end{abstract}

PALABRAS CLAVE:

Biogeografía, caída de hojarasca, fenología, fuente de perturbación, manglares de México, productividad.

\begin{abstract}
The bibliographical information in México's mangroves was reviewed, starting with biogeography. The diversity and composition of mangroves on the two coasts as well as their limits of distribution are described. The distribution, composition and physiognomy of mangrove communities are influenced by the latitudinal changes in the temperature and precipitation, but they depend locally on the geomorphology, the substrate, the salinity, the inundation and the relief. The studies reviewed suggest that the biotic interactions could also influence the observed zonation patterns and that he physiological and ecological optimum of the species do not always coincide spatially. The studies on litterfall have been carried out in the Gulf of México and Pacific Ocean coasts. The papers on leaf decomposition and its dynamic are also reviewed, along with those on phenology and the deforestation estimates which seems to be $5 \%$ per year. Finally, an analysis was made of the sources of mangrove forests perturbation. The main conclusion is that the challenges are very large and that more studies are required.
\end{abstract}

KEY WORDS:

Biogeography, leaf falling, phenology, perturbation sources, México mangroves, productivity. 


\section{INTRODUCCIÓN}

Los manglares en México se distribuyen en el interior de lagunas costeras y sistemas deltáicos de las costas del Golfo de México y del Océano Pacífico, con algunas lagunas costeras que poseen bocas efímeras que se abren durante la temporada de lluvias o por acción de los pescadores. En el Caribe, los manglares se distribuyen en depresiones formadas entre cordones litorales del Pleistoceno, más extensas cuando están frente a barreras arrecifales.

La investigación sobre manglares en México tiene un desarrollo alrededor de 40 años. Las publicaciones que pueden considerarse como pioneras son las de Cuatrecasas (1958, primera en México, pero con ejemplos colombianos), Miranda (1958), Sánchez (1963), Thom (1967) y Vázquez (1971). La primera visión general, puesta en el contexto de la vegetación de México, es la de Rzedowski (1978), quien además presenta en su mapa de vegetación de la República Mexicana la distribución de manglares, considerándola parte de la vegetación acuática y subacuática. Un mapa en donde se proporciona una visión general de la distribución de manglares en México es el de Flores et al. (1971); otros mapas son los publicados por Lot y Novelo (1990) y por Tovilla (1994), aunque también pueden consultarse las cartas publicadas por DETENAL e INEGI durante las tres décadas anteriores. Muy pocas instituciones cuentan con investigadores de manglares, pero existe un entusiasta grupo de estudiantes que va en aumento.

\section{BIOGEOGRAFÍA}

Chapman (1975) reconoció dos grandes regiones biogeográficas de distribución de manglares, ambas comprendiendo los trópicos y subtrópicos: la región del Indo-Pacífico y la del Nuevo Mundo-Oeste de África. La segunda región incluye la costa Atlántica de África y América tropical, la costa Pacífica de
América tropical y las Islas Galápagos. Mientras en África hay diferencias florísticas notables entre sus costas oriental y occidental, éstas son mínimas cuando se comparan con las dos costas de América tropical. Chapman (1975) propuso que durante el Eoceno existió una vía de distribución entre el Pacífico y el Atlántico (Mar de Tetis) y que ésta se cerró definitivamente con la formación del istmo de Centro América en el Plioceno tardío y el Pleistoceno temprano. Rico (1993) presenta una revisión de la literatura en relación con las especies del Continente Americano.

El tiempo en que han permanecido separadas las poblaciones del Pacífico y el Atlántico mexicano parece no haber sido suficiente para generar una diferenciación significativa, al menos para Avicennia germinans (Dodd et al., 2000). El centro de origen y distribución de las especies de manglar sería, bajo esta teoría, la región Indo-Malaya, en donde se han registrado hasta 53 especies de manglar (Chapman, 1975) distribuidas en 12 géneros y 8 familias (Lugo y Snedaker, 1974). Según Chapman (1975), solamente Avicennia y Rhizophora aparecieron lo suficientemente temprano como para migrar satisfactoriamente hacia lo que sería el continente americano y la costa este de África. Laguncularia racemosa, Conocarpus erectus y Pelliciera rhizophorae (restringido ahora en parte de Centroamérica, pero con registros palinológicos del Oligoceno en Simojovel, Chiapas, de acuerdo con Tomasini, 1980; Graham, 1977, 1999 y Jiménez, 1984) son especies arbóreas de manglar exclusivas de la región del Nuevo Mundo-Oeste de África.

En México, las especies de manglar más características son Rhizophora mangle L. (mangle rojo, Rhizophoraceae), Avicennia germinans L. (mangle negro, madre de sal, Avicenniaceae pero anteriormente considerada como Verbenaceae; Nash y Nee, 1984), Laguncularia racemosa (L.) Gaertn. (mangle blanco, Combretaceae) y Conocarpus erectus $\mathrm{L}$. 
(mangle botoncillo, Combretaceae). Rico (1982a) identificó Rhizophora harrisonii Leech. en la costa de Chiapas, en el Pacífico mexicano (lat. $15^{\circ} 10^{\prime} \mathrm{N}$ ), una especie no considerada por Vázquez (1980a, b). Se han encontrado dos especies de mangle negro en la costa de Chiapas (Avicennia germinans y Avicennia bicolor; Jiménez, 1994); las diferencias morfológicas son claras en cuanto al largo y el ancho de las hojas, pero la situación taxonómica debe ser estudiada a profundidad, pues en la práctica $A$. bicolor ha sido considerada como sinonimia de $A$. germinans. Hay dos variedades del mangle botoncillo, Conocarpus erectus (sin indumento foliar) y Conocarpus erectus var. sericeus Grisebach (con indumento foliar), ambas registradas en la costa norte del Estado de Quintana Roo (Miranda, 1958; Tomlinson, 1986; INECOL, 1990). De acuerdo con Tomlinson (1986), Conocarpus erectus no es un mangle verdadero (pues no tiene raíces especializadas y las semillas no germinan en la planta) y es más bien una especie asociada a los manglares, pero es un componente muy importante de los manglares del Caribe en particular. La lista de otras especies asociadas con manglares se presenta en el Apéndice 1, pero son pocas las que se pueden considerar exclusivas de esta comunidad: dos helechos del género Acrostichum y posiblemente una orquídea (Brassavola nodosa, Murren y Ellison, 1998). El resto de las especies también se encuentran en las comunidades aledañas, ya sea en marismas, pantanos de agua dulce, en comunidades de dunas costeras 0 en selvas bajas y medianas.

En relación con el área cubierta por manglares, Flores et al. (1971) calcularon, con base en fotografías aéreas y estudios de campo, que ocupan $14200 \mathrm{~km}^{2}$ (0.7\% del territorio nacional). Por otra parte las área calculadas con la ayuda de imágenes de satélite fueron $6600 \mathrm{~km}^{2}$ (Blasco, 1988 en Flores et al., 1992), $5300 \mathrm{~km}^{2}$ (SARH, 1992) y $9328 \mathrm{~km}^{2}$ (Spalding et al., 1997). Hay, entonces, una diferencia de $8900 \mathrm{~km}^{2}$ entre valores extremos, lo que implica un ámbito de $0.71 \%$ al $0.27 \%$ en términos del área ocupada por manglares en la República Mexicana. En estudios de percepción remota, otras comunidades anegadizas pueden ser confundidas con manglares, por lo que es necesario un extenso trabajo de campo en las costas de la República Mexicana para estimar el valor real.

Como en otros países del Continente Americano, las costas tropicales de México están bajo la influencia climática de un patrón de circulación este-oeste, consecuencia de los vientos alisios. Por tanto, la costa del Golfo de México es en general más húmeda que la costa del Pacífico. Esto se refleja en la diversidad y composición de los manglares. Los del Golfo de México se localizan en zonas protegidas, generalmente en estuarios y lagunas costeras, que reciben agua continental de escorrentía. Lot et al. (1975) definen el límite norte de distribución de manglares en la Laguna Madre (Tamaulipas) aunque estos continúan hacia el sur de Texas y Luisiana, en los EUA. En los alrededores de la Laguna Madre, las temperaturas mínimas llegan a ser menores de $0{ }^{\circ} \mathrm{C}$ durante los meses de noviembre a febrero, la fluctuación de éstas en el ciclo anual es máxima y la precipitación anual es de alrededor de $600 \mathrm{~mm}$. La mayor altura y riqueza específica se encuentra en las extensas lagunas costeras del sur de Veracruz, Tabasco y Campeche, zonas con alta precipitación y con temperaturas nunca menores a $14^{\circ} \mathrm{C}$ (Lot et al., 1975). Estas lagunas están dentro de los sistemas deltáicos de los ríos que desembocan al Golfo (Papaloapan, Coatzacoalcos, Grijalva y Usumacinta). Los manglares continúan por las costas del Golfo de México y el Mar Caribe.

Los cambios latitudinales pueden tener efectos sobre diferentes atributos morfológicos de las plantas. Por ejemplo, Rico y Palacios (1996b) encontraron que el área foliar promedio de Rhizophora mangle se incrementa con la disminución en la latitud (ver también Afzal et al., 
1999). Sin embargo, en un estudio de morfometría floral de Rhizophora mangle en donde compararon poblaciones en diferentes localidades del Golfo y el Pacífico, Domínguez et al. (1998) demostraron que la variabilidad en las flores no seguía un sentido latitudinal, lo que sugiere eventos frecuentes de extinción local y colonización por unos pocos individuos, un acontecimiento que puede estar asociado a huracanes (Kovacs et al., 2001a) o a otros fenómenos poco frecuentes. En la costa del Pacífico, los manglares se encuentran en esteros y lagunas costeras distribuidas más irregularmente que en el Golfo, desde Baja California y Sonora, hasta Chiapas y la frontera con Guatemala. Tovilla (1994) hace una descripción un poco más detallada acerca de la distribución de los manglares en México.

Flores et al. (1992), basándose en una propuesta de Carranza et al. (1975) definen cinco unidades morfotectónicas en la costa del Pacífico:

(1) La costa del Pacífico de la Península de Baja California, con pequeñas cuencas de drenaje y poca escorrentía. En esta zona se localizan 16 lagunas costeras y alrededor del $50 \%$ de éstas tiene manglares;

(2) La costa oeste del Golfo de California, una zona con pendientes muy drásticas, carente de plataforma continental y bajo condiciones de aridez. Aquí se localizan solamente cinco lagunas costeras y los manglares se encuentran en dos bahías (Bahía de la Paz y Bahía de los Ángeles);

(3) La costa este del Golfo de California, con numerosas lagunas costeras; las lagunas más grandes tienen la boca de entrada permanentemente abierta y reciben escorrentía continua. En las pequeñas (como en la laguna $\mathrm{EI}$ Verde, estudiada por Flores et al., (1987) la boca se cierra durante la época seca (en El Verde, de fines de octubre hasta mayo) y se abre durante la época lluviosa debido a la descarga fluvial, que es también estacional. Incluye la zona de Marismas Nacionales, en Nayarit;

(4) Las costas de los estados de Jalisco y Colima, con una estrecha plataforma continental, bajo condiciones áridas o semiáridas y pocas zonas intermareales, lo que reduce el número de hábitats disponibles para los manglares. Las lagunas con bocas efímeras son frecuentes;

(5) Abarca los estados de Oaxaca y Chiapas. Al contrario que la unidad anterior, ésta posee una extensa plataforma continental y por tanto sistemas lagunares extensos. Es aquí donde las comunidades de manglar tienen su máxima altura y diversidad, que probablemente se localiza en el sistema ChantutoTeculapa-Panzacola, en donde se han medido árboles de Rhizophora mangle de hasta $35 \mathrm{~m}$ de altura (Segura y Ramírez 1990, Ramírez y Segura 1994, Montes et al., 1999).

Los manglares son extensos en las costas del Caribe en los estados de Yucatán y Quintana Roo (Trejo et al., 1993). En estas zonas, las comunidades de manglar pueden estar compuestas de casi cualquier combinación de Conocarpus erectus, Rhizophora mangle, Avicennia germinans y Laguncularia racemosa, incluyendo bosques uniespecíficos con árboles de hasta $8 \mathrm{~m}$ de cualquiera de las cuatro especies (INECOL, 1990). La fisonomía de las asociaciones más comunes, las de Rhizophora-Conocarpus son significativamente diferentes de las del Golfo y el Pacífico, debido posiblemente, a la baja tasa de recambio del sistema hidrológico (la influencia de las mareas y de los aportes de agua dulce, Snedaker y Pool, 1973; Lugo y Snedaker, 1974; Pool et al., 1975) derivado del paisaje de carso (karst) de la Península de Yucatán y a la 
influencia del agua saturada de calcio y pobre en nutrientes de las costas y lagunas del Caribe. Los manglares enanos de Rhizophora mangle son las comunidades dominantes de los estuarios del Caribe y de las lagunas que se formaron entre los cordones litorales del Pleistoceno Superior y las extensas formaciones arrecifales (Ward et al., 1985; INECOL, 1990) y frecuentemente forman parte de extensos sistemas de marismas en asociación con la gramínea Cladium jamaicense Crantz (Olmsted et al., 1983; López Portillo et al., 1989).

\section{FISONOMÍA Y COMPOSICIÓN}

Lot et al. (1975) estudiaron los cambios en la fisonomía y composición específica de los manglares y su relación con los cambios latitudinales de la temperatura y la precipitación en el Golfo de México. Estos autores encontraron que los manglares son estructuralmente simples y marcadamente pobres en especies hacia la sección norte del Golfo, en donde la temperatura en enero puede estar por debajo de los $0{ }^{\circ} \mathrm{C}$ y la precipitación anual es de alrededor de 700 $\mathrm{mm}$. En estos sitios hay grandes extensiones de bosques de manglar uniespecíficos con alturas máximas de 3 $\mathrm{m}$ a $4 \mathrm{~m}$ y $\sin$ epífitas ni trepadoras. Hacia el sur del Golfo, en el estado de Veracruz, las temperaturas mínimas en el mes de enero nunca están por debajo de los $14^{\circ} \mathrm{C}$, y la precipitación anual es mayor de $2000 \mathrm{~mm}$. En esta zona tropical húmeda, la complejidad estructural y la diversidad aumentan dramáticamente. En la Laguna de Sontecomapan, al sur de Veracruz (ver también Menéndez, 1976), se encuentran manglares mixtos con Rhizophora mangle (Ángeles, 1997), Avicennia germinans y Laguncularia racemosa. La altura arbórea en esta área es de $25 \mathrm{~m}$ a $30 \mathrm{~m}$, hay trepadoras y epífitas (e.g. Rhabdadenia biflora, Bromelia pinguin, Tillandsia spp.) y crece asociada una rica flora de árboles, arbustos y hierbas perennes de pantano (e.g. Pachira aquatica, Hibiscus tiliaceus, Dalbergia brownei y Acrostichum aureum).
Una de las conclusiones de este estudio es que existe un gradiente biogeográfico en riqueza de especies y complejidad estructural que va desde manglares subtropicales uniespecíficos con poca diversidad y altura hasta bosques de manglar de mayor altura asociados con otras especies tropicales en zonas más húmedas y de mayor temperatura. La primera tesis de licenciatura publicada en México sobre este tema (Zarur, 1961) contiene una breve descripción de los manglares de Laguna de Términos.

Thom (1967 y 1982) en un estudio llevado a cabo en las planicies inundables costeras de Tabasco, encontró una gran dependencia de las variables del substrato, tales como el nivel de inundación, el drenaje del suelo y la salinidad con la geomorfología del sitio. Thom (1967) concluyó que los cambios en la geomorfología contribuyen a explicar las condiciones locales del substrato y por asociación, la composición específica y la estructura de los bosques de manglar.

López Portillo y Ezcurra (1989a) pusieron a prueba las ideas de Thom (1967) a un nivel local, en donde los efectos ambientales podían ser controlados. La altura, el diámetro a la altura del pecho (dap) y la cobertura estaban correlacionadas alta y significativamente $(P<0.01)$ en cada una de las tres especies consideradas (Rhizophora mangle, Avicennia germinans, Laguncularia racemosa). Hubo también una asociación significativa entre la salinidad de la época más extrema y las dos geoformas bajo estudio (planicie lodosa y cuenca interfluvial): el sustrato de las planicies lodosas es extremadamente salino, en tanto que el de las cuencas interfluviales es mucho menos salino, ya que recibe los aportes de los ríos que drenan hacia la laguna. La diversidad de los manglares disminuyó significativamente con el incremento en la salinidad. Mientras que en los sitios menos salinos hay bosques mixtos, los sitios más salinos están ocupados por manglares monoespecíficos de Avicennia. Además, la altura y el dap 
de las tres especies de manglar registradas se incrementaban al disminuir la salinidad. Estas dos variables parecen ser una medida del éxito fisiológico de los individuos de cada especie en el sitio.

La cobertura, por otro lado, parece ser una medida del éxito ecológico de cada especie en la comunidad, pues mide la capacidad de ocupar espacio en relación con sus competidores potenciales y no está necesariamente asociada con las variables individuales (altura y dap). Rhizophora y Laguncularia incrementan su cobertura hacia salinidades menores, lo que sugiere que su óptimo ecológico está cercano a su óptimo fisiológico. Avicennia, sin embargo, incrementó su cobertura hacia salinidades mayores, formando extensos manglares uniespecíficos de baja altura en las planicies lodosas. A pesar de que su óptimo fisiológico se logra en salinidades más bajas, su óptimo ecológico se encuentra en ambientes más salinos. La baja cobertura de Avicennia en substratos menos salinos de las cuencas Interfluviales puede atribuirse al desplazamiento competitivo ejercido por las otras dos especies (López Portillo y Ezcurra 1989a).

Un área de investigación que debe ser abordada tomando como punto de partida los estudios de Snedaker y Pool (1973), Lugo y Snedaker (1974) y Pool et al. (1977), es la relacionada con el achaparramiento de mangles. A pesar de que se han realizado descripciones sobre la vegetación en las costas del Caribe (e.g. López, 1983; Olmsted et al., 1983; Rico, 1982b; Durán, 1987; López Portillo et al., 1989), se conoce muy poco acerca de las causas de la fisonomía de los manglares de las costas calcáreas de Yucatán (Sánchez, 1994). Por ejemplo, pueden observarse árboles de mangle rojo de $8 \mathrm{~m}$ de altura situados a unos cuantos metros de árboles de la misma especie achaparrados (Durán, 1987). La única razón aparente es un cambio en el relieve, ya que no hay diferencias significativas en el contenido de nutrientes del suelo y el agua es prácticamente dulce
(López Portillo et al., 1989; Febles, 1996). Con el fin de entender más acerca de estos manglares, que son una característica notable en la costa del Caribe Mexicano, son esenciales los estudios de las dinámicas estacionales del nivel de inundación y flujo de agua, exportación de sedimentos, salinidad y cambios en el relieve (Rico y Palacios 1996b).

\section{ZONACIÓN VEGETAL E INTERACCIONES ENTRE ESPECIES}

La zonación vegetal en manglares fue primero interpretada como una consecuencia de la sucesión ecológica, un punto de vista fue refutado, entre otros, por Thom (1967), Chapman (1969) y Lugo (1980). También se ha sugerido que la zonación es el resultado de la respuesta diferencial de las especies a gradientes de factores fisiológicamente importantes, tales como la salinidad (Ball y Farquhar, 1984a y 1984b; Mizrachi et al., 1980), el nivel de inundación y los niveles de marea (Hinde, 1954; Adams, 1963) y las propiedades del suelo, incluyendo la fertilidad (Eleuterius y Eleuterius, 1979; Boto y Wellington, 1984; Nickerson y Thibodeau, 1985).

Rabinowitz (1975 y 1978) cuestionó la explicación tradicional de que cada especie ocupa la zona fisiológicamente óptima a lo largo del gradiente ambiental y que estos gradientes son directamente responsables por las zonas de vegetación. Sus investigaciones mostraron que el tamaño del propágulo y la longitud del hipocótilo son factores importantes que condicionan la dispersión de los manglares. Las plántulas con hipocótilos más largos tenderán a establecerse en aguas más profundas, en tanto que las plántulas con hipocótilos más pequeños se establecerán en aguas más someras. De acuerdo con Rabinowitz (1978), la zonación en manglares es el producto de la influencia de la marea en la distribución por tamaños de los propágulos (tidal sorting) mientras estos flotan. La distribución por marea de los propágulos propuesta por Rabinowitz (1978), a pesar 
de estar cuidadosamente apoyada por evidencia experimental no siempre es tan evidente. Esta hipótesis no ha sido demostrada en los manglares más diversos del mundo, en donde no parece haber una relación entre el tamaño del propágalo y la distribución de la especie (Tomlinson, 1986).

Las explicaciones antes mencionadas no son mutuamente excluyentes como posibles causas de la zonación en manglares. Esto es, la zonación puede ser consecuencia conjunta del potencial de dispersión de sus propágulos, de la respuesta de las especies a factores abióticos y de las interacciones competitivas intraespecíficas. En los manglares de México es posible encontrar bosques monoespecíficos o mixtos creciendo en suelos con niveles de inundación comparables. Hay áreas, con un potencial de distribución por mareas semejante, que mantienen especies diferentes; estos cambios en composición posiblemente están relacionados con la salinidad y el ambiente geomorfológico.

Los manglares, como muchas otras plantas, tienen la capacidad de cambiar las propiedades físicas y químicas de los suelos en donde se desarrollan. Un transecto perpendicular a la orilla de la laguna de Mecoacán, Tabasco (López Portillo y Ezcurra, 1989b) atravesó bandas discretas de vegetación que resultan de los cambios en la altura y cobertura de Avicennia germinans y Batis maritima cuando pasan de la planicie lodosa a la marisma y, finalmente, a los suelos altos no inundables. El transecto también indicaba una variación continua de la textura, la salinidad, la sodicidad y la presencia de otros iones inorgánicos en el suelo. Los factores influidos por la vegetación, tales como la temperatura del suelo o la materia orgánica y la capacidad de amortiguación del suelo (esto es, la diferencia entre la acidez real y la acidez potencial, Mengel y Kirkby, 1982), variaron de manera discreta de una banda de vegetación a la otra. Esto puede ser un efecto inducido por las especies sobre su substrato, lo que posiblemente juega un papel importante en la zonación vegetal. EI mangle negro, por ejemplo, generaría un substrato sombreado que no sería tolerado por especies de marismas y otras que colonizan la banda de vegetación superior.

Este efecto de la exclusión de la especie dominante fue probado experimentalmente en la Laguna de Mecoacán (López Portillo y Ezcurra, 1989b) midiendo el establecimiento de Batis maritima en áreas de la planicie lodosa en donde Avicennia germinans fue parcialmente talada hacía aproximadamente 16 años. Se encontró que por cada unidad de manglar removida, una cantidad similar de suelo fue cubierta por Batis, que puede establecerse y crecer en dicha planicie lodosa si se excluye a Avicennia. Parece claro que las interacciones bióticas juegan un papel en los patrones de zonación. En breve, la distribución por mareas de los propágulos, el nivel de inundación y las características propias del suelo (incluyendo las inducidas por el establecimiento de la vegetación) interactúan de una manera compleja, generando la zonación observada.

Otro aspecto de gran importancia es el relacionado con las adaptaciones anatómicas y la posibilidad de que éstas varíen con las condiciones ambientales. Los mangles se encuentran frecuentemente en sitios sujetos a inundación y por tanto bajo condiciones de anoxia en un ambiente salino. Son también frecuentes los suelos muy finos, en donde la difusión de oxígeno en el substrato es lenta. Esto ha dado lugar a diferentes estructuras especializadas como pneumatóforos en Avicennia y Laguncularia y lenticelas en las raíces de zanco de Rhizophora (Chapman, 1974; Tomlinson, 1986). Las estructuras responsables del intercambio de gases entre la atmósfera y las raíces son versátiles; Yáñez et al. (2001) encontraron diferencias importantes en las características de la madera y la corteza con relación a la textura del suelo, la salinidad y nivel de inundación que están relacionadas con el transporte de agua, 
fotosintatos y el intercambio de gases en tres especies de manglar. Aún ahora se está describiendo la forma en la que deben funcionar estas estructuras (Ángeles et al., 2002).

\section{ESTACIONALIDAD EN LA CAÍDA DE HOJARASCA}

A pesar de que los manglares son plantas esclerófilas siempre verdes que tiran sus hojas a lo largo de todo el ciclo anual, tienden frecuentemente a concentrar la caída de hojarasca (que incluye todas las partes vegetales que se desprenden de los árboles) en estaciones determinadas. Esto ha sido registrado en todos los estudios hechos en México sobre el tema. De acuerdo con Pool et al. (1975), "los patrones de caída de hojarasca son sensibles a tensiones del ambiente tales como la salinidad, que incrementa el costo de mantener tejido fotosintético". Por ejemplo, en el Golfo de México, tanto Rico (1979) como López Portillo y Ezcurra (1985) encontraron que tiende a concentrarse entre abril y agosto. Como este período coincide en general, aunque no exactamente, con las lluvias de tipo monzónicas de verano (junioseptiembre), parece haber una relación positiva entre la precipitación y la caída de hojarasca. Sin embargo, López Portillo y Ezcurra (1985) encontraron que la precipitación en sí misma no es un determinante directo de las condiciones hídricas de la Laguna de Mecoacán, ya que hay un considerable intervalo entre los picos de precipitación y los cambios en las condiciones del estuario, lo que se detalla a continuación.

Las condiciones ambientales en el Golfo de México se pueden sintetizar en dos estaciones contrastantes: (a) una estación "seca" de primavera-verano con bajos niveles hídricos en el estuario, altas tasas de evaporación, altas temperaturas e insolación y (b) una estación "húmeda" de otoño-invierno con altos niveles de inundación, baja temperatura y bajas evaporación e insolación. La estación seca se presenta de abril a agosto y la húmeda de septiembre a marzo. Esto es, durante los primeros meses del verano lluvioso las condiciones en la laguna son realmente más secas y extremas que hacia el final del verano, cuando la escorrentía continental descarga agua en los estuarios. Debido a este desfasamiento en el tiempo, la escorrentía continental se sobrepone con las pocas lluvias de invierno.

Para probar la relación entre la caída de partes vegetales y los factores ambientales se optó por llevar a cabo un análisis de componentes principales en donde se consideró la matriz de correlaciones entre la temperatura, el nivel de agua, la evaporación y la insolación; se desechó la precipitación, pues las correlaciones entre ésta y los otros parámetros ambientales no fueron significativas. Los parámetros ambientales pudieron sintetizarse en un eje principal que explicó el $82 \%$ de la variabilidad total de los datos. Los coeficientes de correlación entre las variables y el nuevo eje principal fueron -0.76 (nivel de agua), -0.93 (evaporación), 0.95 (temperatura) y 0.97 (insolación), todos ellos significativos al $1 \%$. No se encontró una correlación significativa entre el eje principal y la caída de hojarasca, pero la caída de hojas exclusivamente estuvo significativamente correlacionada con este eje $(r=0.65$, $P<0.05$, 8 g.l.), lo que indica que cada componente de la hojarasca sigue una secuencia diferente. Los resultados indicaron que la caída de hojas es directamente proporcional al aumento en la evaporación, la insolación y la temperatura e inversamente proporcional al aumento en el nivel de inundación de la laguna.

Las condiciones ambientales en el Pacífico son más extremas que en el Golfo de México. Esto es particularmente notable en el norte, en donde se han desarrollado los estudios de caída de hojarasca correspondientes a la costa oeste de México. Por ejemplo, en la laguna EI Verde $\left(23^{\circ} 35^{\prime}\right.$ de latitud) llueve en promedio $630 \mathrm{~mm}$ al año, pero la lluvia 
se concentra en un período de 4 meses (julio a octubre). Durante ese período, una vez que se acumuló suficiente agua de escorrentía como para crear una fuerte diferencia de niveles entre el interior de la laguna y el nivel del mar, el tapón de la boca de la laguna es erosionado y el agua acumulada se desaloja en un período de horas o de pocos días, dando lugar a una intensa exportación de la hojarasca que no se descompuso durante la época seca (Flores et al., 1987).

La salinidad tiene valores de 10-20 g/l durante la época húmeda, pero su concentración aumenta a más de $30 \mathrm{~g} / \mathrm{l}$, tres meses antes de que se inicien las lluvias y suba con ellas el nivel de la laguna. Es precisamente en este período cuando cae el $70 \%$ del total de la hojarasca registrada en el ciclo anual (Flores et al., 1987).

\section{PRODUCTIVIDAD}

Un parteaguas internacional acerca de la investigación en manglares se inicia con el trabajo de Golley et al. (1962) y puede atribuirse fundamentalmente a los trabajos realizados por Heald (1969) sobre la producción de detritos orgánicos y Odum (1970) sobre la importancia ecológica de los detritos descompuestos en las cadenas alimenticias estuarinas (Snedaker, 1989). Los resultados obtenidos por estos investigadores sirvieron no sólo como impulsores de otras investigaciones científicas relacionadas con la estructura, la composición y la fisiología de los manglares, sino que también han inspirado la base conceptual para demandar la protección de los manglares y así garantizar el mantenimiento de pesquerías alrededor de los estuarios (Snedaker, 1989; Twilley y Day, 1999; Villalobos et al., 1999). Las leyes sobre protección de los manglares son también seguidas por autoridades gubernamen-tales en muchas partes del mundo, incluyendo a la SEMARNAT y sus predecesoras en México.
La caída de hojarasca forma parte de la productividad primaria neta (PPN; otros componentes serían la producción de madera, el incremento en biomasa en pie, lo que incluye tejido aéreo y radical), es uno de los valores de productividad más frecuentemente usados en la literatura y algunos autores han propuesto que constituye la tercera parte de la PPN (Teas, 1979 In Day et al., 1988), aunque Day et al. (1988) describen que en la determinación de valores de PPN para dos sitios en la Laguna de Términos, Campeche, son el doble de los datos obtenidos para la caída de hojarasca y sugieren que antes de aplicarse una proporción constante entre ambos valores deben llevarse a cabo más estudios para documentar dicha relación. Como ya se mencionó, la salinidad del substrato es también importante: Day et al. (1996) encontraron una relación inversa entre ésta y la caída de hojarasca.

En México se han hecho estudios de producción de hojarasca (Tabla 1), en el Golfo de México por Rico (1979), Rico y Lot (1983), López Portillo y Ezcurra (1985) y Day et al. (1988). En la costa del Pacífico dichos estudios han sido publicados por Flores et al. (1987), Ramírez (1987) y Hernández y Espino (1999); probablemente hay otros estudios descritos en tesis profesionales a las que no se tuvo acceso. La zona del Caribe carece de tales estudios. Rico (1979) estudió un bosque de manglar mixto (de tipo cuenca de acuerdo con la clasificación de Lugo y Snedaker, 1974) en una laguna costera en Veracruz y registró una caída media de hojarasca $2.80 \mathrm{~g} \mathrm{~m}^{-2}$ día $^{-1}$ (1 025 $\mathrm{g} \mathrm{m}^{-2}$ año ${ }^{-1}$ ). López Portillo y Ezcurra (1985) estudiaron un manglar monoespecífico de Avicennia germinans en la Laguna de Mecoacán, Tabasco en una planicie lodosa (clasificación de Thom, 1967) encontrando una caída media de $1.68 \mathrm{~g} \mathrm{~m}^{-2}$ día $^{-1}$ (614 g $\mathrm{m}^{-2}$ año-1 ${ }^{-1}$. Day et al. (1988) determinaron que la caída de hojarasca fue de $835 \mathrm{~g} \mathrm{~m}^{-2}$ año ${ }^{-1}$ en una orilla dominada por Rhizophora y $1252 \mathrm{~g} \mathrm{~m}^{-2}$ año-1 en un manglar ribereño (sensu Lugo y Snedaker 1974) con Avicennia germinans como especie dominante. 
Tabla 1. Producción anual de hojarasca en manglares de México

\begin{tabular}{|c|c|c|c|}
\hline LOCALIDAD & $\begin{array}{l}\text { CAÍDA DE } \\
\text { HOJARASCA } \\
\text { PROMEDIO ANUAL } \\
\left(\mathrm{g} / \mathrm{m}^{2}\right)\end{array}$ & TIPO DE MANGLAR & FUENTE \\
\hline \multicolumn{4}{|c|}{ GOLFO DE MÉXICO } \\
\hline La Mancha, Veracruz & 1025 & manglar mixto (transecto lagunar) & (1) \\
\hline Mecoacán, Tabasco & 614 & $\begin{array}{l}\text { manglar de Avicennia } \\
\text { (planicie lodosa) }\end{array}$ & (2) \\
\hline \multirow[t]{2}{*}{ Términos, Campeche } & $1252-1653$ & $\begin{array}{l}\text { dominado por Avicennnia } \\
\text { (ripario) }\end{array}$ & $(3,4)$ \\
\hline & $657-835$ & dominado por Rhizophora (orilla) & $(3,4)$ \\
\hline \multicolumn{4}{|c|}{ COSTA DEL PACÍFICO } \\
\hline El Verde, Sinaloa & 1100 & $\begin{array}{l}\text { Laguncularia racemosa } \\
\text { (orilla) }\end{array}$ & (5) \\
\hline \multirow{4}{*}{ Agua Brava, Nayarit } & 1417 & $\begin{array}{l}\text { dominado por Laguncularia (5) } \\
\text { (orilla) }\end{array}$ & (6) \\
\hline & 1263 & $\begin{array}{l}\text { dominado por Laguncularia } \\
\text { (cuenca) }\end{array}$ & (6) \\
\hline & $521 \pm 60$ bajo & $\begin{array}{l}\text { Manglares de cuenca } \\
\text { monoespecíficos }\end{array}$ & (6) \\
\hline & 1015 & $\begin{array}{l}\text { dominado por Laguncularia } \\
\text { (ripario) }\end{array}$ & (6) \\
\hline $\begin{array}{l}\text { Barra de Tecoanapa, } \\
\text { Guerrero }\end{array}$ & 949 & Bosque de Conocarpus erectus & (7) \\
\hline
\end{tabular}

Caída de hojarasca anual en otros manglares (promedio de valores publicados, Twilley et al., 1986)

\begin{tabular}{|c|c|c|}
\hline TIPO DE MANGLAR & $\begin{array}{l}\text { TOTAL MEDIO ANUAL DE } \\
\text { RECAMBIO DE AGUA }\end{array}$ & $\begin{array}{l}\text { HOJARASCA } \pm \text { EE } \\
\left(\mathrm{g} / \mathrm{m}^{2}\right)\end{array}$ \\
\hline Manglares enanos & muy bajo & $186 \pm 55$ \\
\hline Manglares de cuenca mixtos & intermedio & $835 \pm 61$ \\
\hline Manglares de orilla & alto & $900 \pm 72$ \\
\hline Manglares riparios & muy alto & $1298 \pm 101$ \\
\hline
\end{tabular}


En el Pacífico, la caída de hojarasca fue de $1100 \mathrm{~g} \mathrm{~m}^{-2}$ año-1 en un manglar de Laguncularia racemosa ubicado en una laguna de Sinaloa cuya boca de entrada es efímera (Flores et al., 1987), mientras que en el Estado de Nayarit se registraron valores de 1417,1263 y $1015 \mathrm{~g} \mathrm{~m}^{-2}$ año ${ }^{-1}$ en tres localidades dentro de la Laguna Agua Brava, donde Laguncularia racemosa es también la especie dominante (Ramírez, 1987). Por último, sólo hay un trabajo en donde se presentan valores de caída de hojarasca en Conocarpus erectus (Hernández y Espino, 1999), y la cantidad es intermedia: $949 \mathrm{~g} \mathrm{~m}^{-2}$ (Tabla 1). Los resultados del Golfo de México y el Pacífico están dentro de los ámbitos de valores compilados por Twilley et al. (1986), pero los manglares de Laguncularia parecen haber producido una mayor cantidad de hojarasca (Tabla 1). Flores et al. (1987) sugieren, siguiendo a Pool et al. (1975), que la causa de esta mayor producción puede ser una alta tasa de recambio de agua (que definen como la razón de la entrada de agua dulce entre el volumen de agua en la laguna) en su sitio de estudio.

Desde la óptica de la contribución de los manglares a la productividad de los estuarios, es necesario conocer el destino de la hojarasca: qué porcentaje se descompone in situ y qué proporción es exportada hacia otras partes del sistema estuarino y al sistema marino adyacente. Hay algunos trabajos publicados en México en donde se presentan estudios de ésta índole (Day et al., 1988 y 1996; Flores et al., 1987; Vega y Arreguín, 2001). Flores et al. (1987) indican que la descomposición de hojarasca colocada en bolsas en suelos inundados es más rápida que la descomposición en suelos altos y secos: después de 6 meses de colocadas las bolsas restaba el $21 \%$ y $73 \%$ del peso inicial en condiciones de humedad y de sequía, respectivamente (ver también Contreras, 1993). La hojarasca que no se descompone o que cae durante la época seca puede ser desplazada del sitio en donde se originó si hay un aumento considerable del nivel de agua y si ésta es desalojada en un corto período, tal como sucede típicamente en lagunas costeras con bocas efímeras.

Los componentes orgánicos de la hojarasca pueden estar en dos estados, de acuerdo al grado de descomposición de ésta: como materia orgánica particulada (MOP), y como materia orgánica disuelta (MOD). Si la hojarasca se descompone in situ (como sucede en los manglares que se encuentran en cuencas bajo condiciones de inundación constante) la materia orgánica que se exporta es en forma disuelta; si los manglares se encuentran en zonas en donde el flujo de agua es constante, como en las orillas, la materia orgánica que se exporta es en forma particulada (Twilley 1985). Snedaker (1989) propone que "el área completa de la química ecológica estuarina (la gran variedad de compuestos lábiles y persistentes que se encuentran en la MOD) está ampliamente abierta para los cuestionamientos inteligentes y la investigación" y menciona tres posibles papeles que puede desempeñar la MOD: (1) como una fuente alternativa de alimento que es inicialmente colonizada por microorganismos que son consumidos por crustáceos (Camilieri y Ribi, 1986); (2) como la base de cadenas alimenticias de organismos heterotróficos que contribuye en gran medida a la productividad de la columna de agua (Snedaker, 1989); y (3) como una fuente de claves químicas (positivas o negativas) que controlan la distribución espacial y temporal de las especies estuarinas (Alongi, 1987; Valiela et al., 1979; Cooksey et al., 1975).

\section{FENOLOGÍA}

Son pocos los estudios que han utilizado la caída de las partes vegetativas que componen la hojarasca de los manglares como un indicador de la fenología. Aunque todavía es prematuro definir patrones generalizables, lo obtenido hasta ahora sugiere que cada componente morfológico individual tiene un ciclo por sí mismo. En Mecoacán, Tabasco (López Portillo y Ezcurra, 1985), 
el $83 \%$ de la caída anual de hojarasca consistió de hojas, $9 \%$ de ramas, $6 \%$ de flores abortadas y partes florales y $2 \%$ de propágulos. A pesar de que las ramas caen a lo largo de todo el año, existen dos picos estacionales: el primero ocurre cuando la planta tira las flores abortadas y el segundo pico ocurre un mes después de que la planta ha tirado sus propágulos. Avicennia produce flores en julio y agosto, cuando predominan las condiciones de sequía en la laguna, pero esta floración temprana garantiza la supervivencia de los propágulos, ya que estos sufren abscisión en diciembre, cuando la estación favorable tiene su inicio (ver también Rico, 1979). Por otro lado, Rhizophora produce flores a lo largo de todo el año, pero dicha producción disminuye durante los meses desfavorables (marzo a agosto) (Rico, 1979). Sus propágulos caen durante casi todo el año, excepto entre febrero y mayo, la estación más seca y con el más bajo nivel de inundación.

En conclusión, ambas especies muestran estrategias de floración contrastantes, pero los períodos durante los cuales caen los propágulos son más convergentes. En tanto que Avicennia puede aparentemente optimizar de una manera más precisa que Rhizophora la temporada de producción de propágulos, tiene que pagar el costo fisiológico de florecer en la época cuando las condiciones ambientales son de sequía. Por otro lado, Rhizophora florece en la época húmeda, pero muestra un período de floración más prolongado y sus propágulos pueden establecerse durante la época seca, cuando el nivel del agua es bajo y la salinidad es máxima. Esta especie retiene sus propágulos por períodos más largos (Tovilla, 2001 com. pers.), lo que implica un costo parental mucho mayor que el de Avicennia.

Para ambas especies, la correlación significativa entre la variación ambiental y la caída de propágulos sugiere que esta sincronización tiene valor adaptativo. Jiménez (1988) encontró un patrón similar en los manglares de Costa Rica, en donde cuatro especies diferentes de manglar con eventos de floración desfasados en el tiempo tiraron sus propágulos entre los meses de agosto a diciembre, los meses en que el nivel de inundación es mayor y la salinidad del agua disminuye. Estas hipótesis parecen tener bases fisiológicas: Rabinowitz (1978) demostró que la vida media de los propágulos de Avicennia es mayor en agua dulce que en agua salada y que un alto nivel de inundación es esencial para la dispersión de estos.

\section{PRESIONES ANTROPÓGENAS}

Como en todas las comunidades naturales de México, los desmontes y la substitución por zonas transformadas han provocado una disminución de la cobertura natural de los manglares que se conoce con poca precisión. Spalding et al. (1997) estiman un cambio en zonas conservadas de $15000 \mathrm{~km}^{2}$ a $5315 \mathrm{~km}^{2}$ en un intervalo de 22 años (1970-1992), una tasa anual de deforestación de $2.9 \%$. Sin embargo, la tasa debe ser mucho mayor si se considera que ésta aumentó en los últimos 20 años. Rodolfo Dirzo (Dirzo, 1994 com. pers.) calculó que la tasa anual de deforestación en México es de $5 \%$, pero que en el Caribe alcanza casi el $12 \%$ (otras regiones: $3.9 \%$ Golfo de México y $4.5 \%$ en el Pacífico). Realmente se carece de datos fidedignos acerca del área afectada de manglares en la República Mexicana. Utilizando imágenes de satélite, Ramírez et al. (1998) calcularon que de 1970 a 1993 se perdió un $23 \%$ de las 1065 hectáreas de un manglar en Nayarit. Una cifra similar se ha calculado para Sinaloa (Ruiz y Berlanga, 1999). Aunque las especies de manglar están consideradas bajo protección especial en la NOM-ECOL-059/2001 (SEMARNAT, 2002) y el uso, restauración y conservación de los manglares está regido por la NOM-EM-001-RECNAT1999 (SEMARNAT, 1999), la falta de definición respecto a quién es realmente el dueño de las comunidades de manglar (¿son propiedad federal? Si lo son, ¿bajo qué criterios deben darse las concesiones 
para su manejo, substitución o explotación?) los vuelve particularmente vulnerables.

La situación geográfica de los manglares en estuarios, lagunas costeras y planicies inundables conduce a un conflicto entre el uso que se quiere dar a las costas y la conservación de esta comunidad de la zona intermareal. Hasta los años 60 del siglo pasado, antes de que se demostrara su importancia como sitios de refugio y fuentes de alimentación de los organismos estuarinos, los pantanos de manglar se consideraban como áreas insalubres, criaderos de mosquitos, zonas que deberían ser "mejoradas" para cultivos y este criterio aún prevalece en algunos desarrollistas. Como la presión sobre el suelo no fue alta en esa época, estas comunidades se conservaron en general, en buen estado. Sin embargo, es cada vez más difícil no afectar los manglares a medida que el desarrollo invade las zonas costeras.

Los manglares pueden ser afectados de manera directa o indirecta. De manera directa, cuando son cortados para la extracción de madera y utilizados en postería, cimbra para construcción, como carbón y leña (Hernández y Espino, 1999), elaboración de tapos en pesquería y construcción de galerías para secado del tabaco (Kovacs, 1999) o para la extracción de taninos. En la Laguna de Mecoacán, Tabasco, los ejidatarios han extraído los árboles más altos y derechos, - los árboles de diámetros aproximados de $10 \mathrm{~cm}$ cuando necesitan establecer límites entre propiedades. Sin embargo, otros ejidatarios recibieron de la SEDUE un permiso de explotación en un área cercana a los Ríos Hondo y Cuxcuchapa (Castillo, 1994 com. pers.), en donde se encuentra uno de los bosques mixtos de mayor altura y diversidad (López Portillo y Ezcurra 1989a). Hubo una gran densidad de troncos ya cortados al lado de los caminos en el área antes mencionada y no parecía haber una selección por tamaño ni entresacado. Es posible que este patrón de explotación se repita a lo largo de las zonas en donde la presión demográfica es alta y los medios económicos escasos. Es necesario evaluar el impacto de esta manera de extracción para poder hacer algo al respecto, ya que es posible que otras actividades económicas se vean afectadas por este estilo de explotación.

El efecto indirecto de perturbación de manglares es quizás el más generalizado y se da de manera frecuente cuando se construyen caminos o carreteras, cuando se urbanizan zonas costeras 0 se construyen desarrollos turísticos, y cuando se llevan a cabo obras de infraestructura para la explotación y transporte de petróleo o líneas de distribución de energía eléctrica.

\section{Caminos de terracería y carreteras}

En Quintana Roo y Yucatán, por ejemplo, las carreteras y terracerías interrumpen el flujo superficial de agua en los manglares, alterando la tasa de recambio y la salinidad de las aguas que bañan los sistemas radicales, con lo que se provoca la mortalidad de grandes extensiones de manglar (Trejo et al., 1993). Por ejemplo, en el camino que conduce a Punta Allen, en la Reserva de la Biosfera de Sian Ka'an se obtuvo una salinidad de $5 \mathrm{~g} / \mathrm{l}$ en una zona de manglar achaparrado con buen drenaje y $48 \mathrm{~g} / \mathrm{l}$ al otro lado del camino, que fungía como dique a la circulación de agua dulce (López Portillo et al., 1989). Esto ocasionó la muerte de alrededor de 20 ha de mangle, incluyendo algunas partes con Avicennia germinans. Otro ejemplo, también en Quintana Roo, es el del camino que conduce de la carretera Cancún-Chetumal a Puerto Morelos. Este camino atraviesa una comunidad de Conocarpus erectus con Rhizophora mangle. La medición de salinidad del lado norte de la carretera fue de $4 \mathrm{~g} / \mathrm{l}$, en tanto que la del lado sur fue el doble (INECOL, 1990). Aunque la diferencia no fue tan marcada como la del camino a Punta Allen, el paso del huracán Gilberto en 
septiembre de 1988 ocasionó una intrusión de agua marina que drenó rápidamente en el lado norte, pero que permaneció por un largo período en el lado sur, provocando la muerte de una cantidad significativa de individuos de manglar. La solución a este problema es relativamente sencilla y económica; colocar alcantarillas para facilitar el flujo de agua de un lado al otro del camino.

\section{Urbanización y desarrollo turístico}

En este caso, el efecto sobre los manglares es definitivo, ya que se realizan obras de relleno que afectan localmente las comunidades de manglar, pero que también pueden entorpecer el patrón de circulación superficial. La amenaza potencial más grande es la del establecimiento de megaproyectos turísticos, que pueden afectar hasta 4000 hectáreas. Ejemplos de este tipo de proyectos se pueden documentar en la Riviera Maya (o Corredor Cancún-Tulum) y en algunos destinos turísticos de la Península de Baja California.

\section{Infraestructura petrolera}

El establecimiento de campos de explotación y procesamiento, y de tubería de conducción de petróleo y gas ha causado serios problemas en la zona baja de los estados de Tabasco, Veracruz y Campeche. Rico (1979) observó una alta mortalidad de las plántulas que había marcado para estudios de demografía en la Laguna de la Mancha, Veracruz y se la atribuyó al cierre de la boca tras la instalación superficial por PEMEX de un gasoducto. Aunque el gasoducto ha sido enterrado, el tiempo que interrumpió la libre circulación de agua y la emisión de sedimentos al mar a través de la boca de la laguna fue suficiente para azolvar esa área y reducir los rendimientos de ostión. Los esfuerzos para desazolvar la Laguna de La Mancha han sido onerosos e infructuosos.
Otro problema es el vertido de petróleo alrededor de los campos petroleros y las fugas ocasionales debidas a la rotura de líneas de conducción. Zavala (1988) encontró que los derrames de petróleo tienden a acumularse en zonas bajas mal drenadas, pero que cuando el derrame ocurría sobre corrientes de agua, el efecto era mucho mayor debido a la dispersión del petróleo. Como las raíces de mangle contienen lenticelas en donde se realiza el intercambio de gases (Scholander et al., 1955), una delgada capa de petróleo puede provocar la muerte por asfixia.

\section{Instalación de líneas de distribución de energía eléctrica}

Esto afecta a los individuos que se encuentran a lo ancho de la zona que debe ser desmontada para la instalación y mantenimiento de las líneas de conducción. El efecto es muy somero en comunidades de baja altura, pero más severo cuando se tienen que atravesar manglares altos.

Una actividad reciente en la costa del Pacífico es la instalación de estanques para piscicultura, especialmente el cultivo de camarón, así como la apertura de barras para cambiar la salinidad del estuario e inducir la entrada de crías. Los errores cometidos en Ecuador parecen haber permeado en los reglamentos para la construcción de la infraestructura necesaria, pero faltan evaluaciones acerca del impacto a mediano y largo plazo de estas instalaciones (Páez, 2001). Sobre todo, es necesario integrar los conocimientos adquiridos en los manglares con los relacionados con las pesquerías y otras actividades económicas costeras (Yáñez et al., 1999; Barbier, 2000), integrando a esto la percepción y conocimiento de los pobladores locales (Kovacs, 2000; Kaplowitz, 2001; Kovacs et al., 2001a).

Otra actividad que modifica la estructura de las comunidades de manglar es la apertura de bocas (en Tabasco, las 
Lagunas Machona y Tupilco, López y Zavala, 1988), lo que propicia la entrada de la cuña de agua salina y desencadena un proceso de sustitución de pantanos de agua dulce como popales y tulares por manglares de Laguncularia racemosa (Castillo, 1994 com. pers.). En contraste, la apertura de barras en el Pacífico ha tenido efectos muy graves, ya que cientos de hectáreas de manglar de Laguncularia racemosa han muerto por la pérdida de substrato y el aumento en la salinidad (Kovacs et al., 2001b; (Flores , 2002 com. pers.). Es urgente documentar y difundir la gravedad de este tipo de acciones para que las autoridades competentes puedan evitarlos.

\section{COMENTARIOS FINALES}

Aún no han sido abordados los estudios de aspectos más particulares de la anatomía y ecofisiología, la fenología, los sistemas reproductivos, la dispersión y reclutamiento, la interacción entre especies (incluyendo polinización, depredación y mutualismos, p. e. Rico, 1980) y la fisonomía de las comunidades de manglar (Leticia et al., 2000). Para restaurar comunidades de manglar es fundamental comprender la demografía y la estructura de tamaños en comunidades naturales y manejadas experimentalmente (Toledo et al., 2001; Tovilla et al., 2001) con el fin de entender las dinámicas que se llevan a cabo entre unas pocas especies vegetales pero que resultan en comunidades muy complejas. Es necesario saber qué es lo que se tiene y en qué estado de conservación. Es necesario desarrollar una visión de conjunto que incluya el conocimiento de sus usos y fuentes de perturbación local, su valuación económica y su relación con otros ecosistemas terrestres y marinos. Los esfuerzos con enfoque multidisciplinario como el desarrollado por Villalobos et al. (1999) en Laguna de Términos, Campeche deben ser promovidos entre los grupos de trabajo que se forman y están formando en todo México. Un avance significativo en este sentido lo ha dado la Comisión
Nacional para el Conocimiento y Uso de la Biodiversidad al dar a conocer un listado que incluye 64 regiones costeras que terminan por contener toda la distribución de los manglares de México (Arriaga et al., 1998).

En mayo de 1992, con vistas a la reunión de Río de Janeiro (la segunda conferencia sobre el ambiente y el desarrollo), la International Timber Organization (ITTO) y la Internacional Society for Mangrove Ecosystems (ISME) realizaron dos talleres de trabajo (Lacerda y Schaeffer, 1999) en donde se redactaron tres objetivos que son válidos aún, especialmente en México:

1. Revisar el estado actual de los bosques de manglar, incluyendo una evaluación de los datos disponibles sobre su área total, distribución, biodiversidad, geoquímica e Interacciones antropogénicas.

2. Determinar las formas de utilización de los manglares y su importancia socioeconómica incluyendo una visión de conjunto sobre los impactos ambientales principales antropogénicos sobre estos bosques.

3. Identificar y proponer estrategias de manejo y métodos, necesidades de investigación futuras y políticas a ser introducidas en la región para propiciar una utilización sustentable y el manejo razonable de los bosques de manglar.

La mayoría de las investigaciones sobre manglares en México han estado asociadas a diferentes aspectos de su productividad (una línea de investigación cuyo ascendiente directo es el trabajo clásico de Golley et al., 1962), principalmente a través del análisis de la caída de hojarasca. Otro aspecto que ha servido como paradigma es el de la estructura y composición de los bosques de manglar, una línea inspirada por los trabajos de Snedaker y Pool (1973) y Pool et al. (1975). Muchos más estudios deben llevarse a cabo en estas dos líneas de investigación. Los patrones particulares 
son frecuentemente contradictorios, como puede verse, por ejemplo, en los registros sobre caída de hojarasca relacionados con diferentes especies o comunidades. Los estudios comparativos acerca de las variaciones estacionales entre las dos costas del país permitirían comprender más cabalmente estos sistemas.

Son muchos los retos que enfrentan los ecólogos de manglares, desde el estudio de aspectos asociados con su biología y a las historias de ciclo de vida de cada especie hasta temas relacionados con la valuación y el manejo de estos ecosistemas. Desde luego, esto incluye un urgente conocimiento acerca de su distribución en las costas de la República Mexicana y las diferentes formas en que los manglares y las cuencas que drenan hacia ellos son afectados por actividades humanas.

\section{REFERENCIAS}

Adams, D.A. 1963. Factors influencing vascular plant zonation in North Carolina salt marshes. Ecology 44(3):445-456.

Afzal R., Z.; R.S. Dodd y M.T. Fauvel. 1999. A case of natural selection in Atlantic-East-Pacific Rhizophora. Hydrobiologia 413:1-9.

Alongi, D.M. 1987. The influence of mangrove-derived tannins on intertidal meiobenthos in tropical estuaries. Oecologia (Berlin) 7:537-540.

Ángeles, G. 1997. Rhizophora mangle (mangle rojo) In: E. González Soriano, R. Dirzo y R. Voigt, eds. Historia natural de Los Tuxtlas. Instituto de Biología, Instituto de Ecología y Comisión Nacional para el Conocimiento y Uso de la Biodiversidad. Universidad Nacional Autónoma de México, México, D.F. p:148-149.
Ángeles, G.; J. López Portillo y F. Ortega E. 2002. Functional anatomy of the secondary xylem of roots of Laguncularia racemosa (L.) Gaertn. (Combretaceae). Trees. Structure and Function 16:338-345.

Arriaga C., L.; E. Vázquez D.; J. González C.; R. Jiménez; E. Rosenberg; L. Muñoz Y V. Aguilar S. (coord.). 1998. Regiones marinas prioritarias de México. Comisión Nacional para el Conocimiento y uso de la Biodiversidad. México. http://www.conabio. gob.mx/rmp/rmp.html

Ball, M.C. y G.D. Farquhar. 1984a. Photosynthetic and stomatal responses of two mangrove species, Aegiceras corniculatum and Avicennia marina, to long-term salinity and humidity conditions. Plant Physiology 74:1-6.

Ball, M.C. y G.D. Farquhar. 1984b. Photosynthetic and stomatal responses of the grey mangrove, Avicennia marina, to transient salinity conditions. Plant Physiology 74:7-11.

Barbier, E.B. 2000. Valuing the environment as input: review of applications to mangrove-fishery linkages. Ecological Economics 35(1):47-61.

Barreiro G., M.T. 1999. Mangrove leaf litter input and foliage renovation of an estuarine system in southeast Mexico. Revista de Biología Tropical 47(4):729-737.

Boto, K.G. y J.T. Wellington. 1984. Soil characteristics and nutrient status in a northern Australian mangrove forest. Estuaries 71:61-69.

Camilieri, J.C. y G. Ribi. 1986. Leaching of dissolved organic carbon (DOC) from dead leaves, formation of flakes form DOC, and feeding on flakes by crustaceans in mangroves. Marine Biology 91:337-344. 
Carranza E., A.; M. Gutiérrez E. y R. Rodríguez T. 1975. Unidades morfotectónicas continentales de las costas mexicanas. Anales del Centro de Ciencias del Mar y Limnología 2(1):81-88.

Castillo, O. 1994. Comunicación personal.

Contreras E., F. 1993. Ecosistemas costeros mexicanos. Comisión Nacional de Biodiversidad y Universidad Autónoma Metropolitana Iztapalapa. México, D.F. 415 p.

Cuatrecasas, J. 1958. Introducción al estudio de manglares. Boletín de la Sociedad Botánica de México 23:84-99.

Cooksey, K.E.; B. Cooksey; P.M. Evans y E.L. Hildebrand. 1975. Benthic diatoms as contributors to the carbon cycle in a mangrove community. In: L.G. Persoone y K. Jaspers, eds. 10th European Symposium on Marine Biology 2: population dynamics. Sept. 17-23. University Press, Wetteren, Bélgica. Ostend, Bélgica. p:165-178.

Chapman, V.J. 1969. Lagoons and mangrove vegetation. In: A. Ayala C. y F.B. Phleger, eds. Lagunas costeras: Un simposio. Universidad Nacional Autónoma de MéxicoUNESCO No. 28-30. México. p:505-514.

Chapman, V.J. 1974. Mangrove vegetation, Cramer-Verlag. Berlín. 444 p.

Chapman, V.J. 1975. Mangrove biogeography. In: G.E. Walsh, S.C. Snedaker y H.T. Teas, eds. Proceedings of the International Symposium on Biology and Management of Mangroves Vol.1. Universidad de Florida. Gainesville. p:3-22.

Day, J.W. Jr.; W.H. Conner; F. Ley-Lou, R.H. Day y A. Machado. 1988.
Productivity and composition of mangrove forests at Boca Chica and Estero Pargo. In: Yáñez A., A. y J.D. Day, Jr., eds. Ecology of Coastal Ecosystems in the Southern Gulf of Mexico: The Terminos Lagoon Region. Instituto de Ciencias del Mar y Limnología. Universidad Nacional Autónoma de México - Coastal Ecology Institute, Louisiana State University. Editorial Universitaria, México, D.F. p:237-258.

Day, J.W.; C. Coronado M.; F.R. Vera H.; R.R. Twilley R.; V.H. Rivera M.; H. Alvarez G.; R. Day y W. Conner. 1996. A 7-year record of aboveground net primary production in a southeastern Mexican mangrove forest. Aquatic Botany 55(1):39-60.

Dirzo, R. 1994. Comunicación personal.

Dodd, R.S.; Z. Afzal R. y A. Bousquet M. 2000. Evolutionary divergence in the pan-Atlantic mangrove Avicennia germinans. New Phytologist 145(1): 115-125.

Domínguez, C.A.; L.E. Eguiarte; J. Núñez F. y R. Dirzo. 1998. Flower morphometry of Rhizophora mangle (Rhizophoraceae): geographical variation in Mexican populations. American Journal of Botany 85(5): 637-643.

Durán, R. 1987. Descripción y análisis de la estructura y composición de la vegetación de los petenes del noroeste de Campeche, México. Biótica 12(3):181-198.

Eleuterius, L.N. y C.K. Eleuterius. 1979. Tide levels and salt marsh zonation. Bulletin of Marine Sciences 29: 394-400.

Febles P., J.L. 1996. Fluctuación diurna del nivel hidrostático en retenes en la cuenca costera noroccidental del estado de Yucatán: efecto del desazolve y canalización de manantiales. 
Tesis de licenciatura, FMVZ. Universidad de Yucatán.

Flores M., G.; J. Jiménez; X. Madrigal; F. Moncayo y F. Takaki. 1971. Memorias del mapa de tipos de vegetación de la República Mexicana. Secretaría de Recursos Hidráulicos. México.

Flores V., F.J. 2002. Comunicación personal.

Flores V., F.J.; J.W. Day, Jr. y R. Briseño D. 1987. Structure, litter fall, decomposition, and detritus dynamics of mangroves in a Mexican coastal lagoon with an ephemeral inlet. Marine Ecology - Progress Series 35:83-90.

Flores V., F.; F. González F.; D. Segura Z. y P. Ramírez. 1992. Mangrove ecosystems of the Pacific Coast of Mexico: distribution, structure, litterfall and detritus dynamics. In: U. Seeliger, ed. Coastal Plant Communities in Latin America. Academic Press, Nueva York. p:269-288.

Golley, F.B.; H.T. Odum y R.F. Wilson. 1962. The structure and metabolism of a Puerto Rican red mangrove forest in May. Ecology 43:9-19.

Graham, A. 1977. New records of Pelliceria (Theaceae/Pelliceriacae) in the Tertiary of the Caribbean. Biotropica 9(1):48-52.

Graham, A. 1999. Studies in neotropical paleobotany. XIII. An Oligo-Miocene palynoflora from Simojovel (Chiapas, Mexico). American Journal of Botany $86(1): 17-31$.

Heald, E.J. 1969. The production of organic detritus in a south Florida estuary. Tesis de doctorado, Universidad de Miami, Coral Gables, Miami. 111p.

Hernández, C.T. y G.D. Espino. 1999. Ecology, production and use of mangrove, Conocarpus erectus L., in
Barra de Tecoanapa (Guerrero, Mexico). Biotropica 31(1):121-134.

Hinde, P.R. 1954. The vertical distribution of salt marsh phanerogams in relation to tide levels. Ecological Monographs 24:209-225.

Instituto de Ecología, A.C. (INECOL). 1990. Estudios de ecología costera y determinación de zonas de preservación ecológica del Corredor Turístico Cancún-Tulum. Reporte técnico presentado a FIDECARIBE, Secretaría de Turismo, México. 90+viii p., 16 mapas.

Jiménez, J.A. 1984. A hypothesis to explain the reduced distribution of the mangrove Pelliciera rhizophorae Tr. \& PI. Biotropica 16:304-308.

Jiménez, J.A. 1988. Floral and fruiting phenology of trees in a mangrove forest on the dry Pacific coast of Costa Rica. Brenesia 29:33-50.

Jiménez, J.A. 1994. Los manglares del Pacífico Centroamericano. Editorial Fundación UNA. Heredia, Costa Rica.

Kaplowitz, M.D. 2001. Assessing mangrove products and services at the local level: the use of focus groups and individual interviews. Landscape and Urban Planning 56(1-2):53-60.

Kovacs, J.M. 1999. Assessing mangrove use at the local scale. Landscape and Urban Planning 43(4):201-208.

Kovacs, J.M. 2000. Perceptions of environmental change in a tropical coastal wetland. Land Degradation and Development 11(3):209-220.

Kovacs, J.M.; M. Blanco C.; F. Flores V. 2001a. A logistic regression model of hurricane impacts in a mangrove forest of the Mexican Pacific. Journal of Coastal Research 17(1):30-37. 
Kovacs, J.M.; J.F. Wang y M. Blanco C. 2001b. Mapping disturbances in a mangrove forest using multi-date landsat TM imagery. Environmental Management 27(5):763-776.

Lacerda, L.D. y Y. Schaeffer N. 1999. Mangroves in Latin America: the need for conservation and sutainable utilization. In: A. Yáñez A. y A.L. Lara D. eds. Ecosistemas de manglar en América Tropical. Instituto de Ecología, A.C. México, UICN/ORMA, Costa Rica, NOAA/NMFS, Silver Spring MD, EUA. p:5-7.

Leticia, H.M.; R. Foroughbakhch; A.E. Céspedes; E.E. Ponce M. y J.L. Hernández P. 2000. Dispersion and recruitment of three mangrove species in the tropical area of the Gulf of Mexico. Phyton - International Journal of Experimental Botany 66:33-37.

López, R. y J. Zavala. 1988. Impacto de la industria petrolera en zonas inundables del estado de Tabasco. Memorias del Simposio sobre Ecología y Conservación del delta de los Ríos Usumacinta y Grijalva. Gobierno del Estado de Tabasco INIREB-División Regional Tabasco. p:637-643.

López O., A. 1983. Mapa de vegetación y uso del suelo de la Reserva de la Biósfera de Sian Ka'an. In: Sian Ka'an: Estudios preliminares de una zona en Quintana Roo propuesta como Reserva de la Biósfera (Mapa anexo) CIQRO-SEDUE. Cancún, México.

López Portillo, J. 1982. Ecología de manglares y de otras comunidades de halófitas en la costa de la Laguna de Mecoacán, Tabasco. Tesis de licenciatura, Universidad Nacional Autónoma de México. México. 160 p.

López Portillo, J. y E. Ezcurra. 1985. Litter fall of Avicennia germinans $L$. in a one-year cycle in a mudflat at the
Laguna de Mecoacán, Tabasco, Mexico. Biotropica 17(3):186-190.

López Portillo, J. y E. Ezcurra. 1989a. Response of three mangroves to salinity in two geoforms. Functional Ecology 3:355-61.

López Portillo, J. y E. Ezcurra. 1989b. Zonation in mangrove and salt marsh vegetation at Laguna de Mecoacán, Mexico. Biotropica 21(2):107-114.

López Portillo, J.; E. Ezcurra y J.M. Maass. 1989. Los petenes de Sian Ka'an, Quintana Roo y su relación con gradientes de presión hídrica. Acta Botánica Mexicana 5:19-29.

Lot H, A.; C. Vázquez Y. y F.L. Menéndez. 1975. Physiognomic and floristic changes near the northern limit of mangroves in the Gulf Coast of Mexico. In: G.E. Walsh, S.C. Snedaker y H.T. Teas, eds. Proceedings of the International Symposium on Biology and Management of Mangroves Vol.1. Universidad de Florida, Gainesville. p:52-61.

Lot H., A. y A. Novelo. 1990. Forested wetlands of Mexico. In: A.E. Lugo; M. Brinson y S. Brown eds. Ecosystems of the World: forested wetlands. Elsevier, Amsterdam, Holanda p: 287-298.

Lugo, A.E. 1980. Mangrove ecosystems: successional or steady state? Biotropica 12:67 72.

Lugo, A.E. y S.C. Snedaker. 1974. The ecology of mangroves. Annual Review of Ecology and Systematics 5:39-64.

Menéndez L., F. 1976. Los manglares de la Laguna de Sontecomapan, Los Tuxtlas, Veracruz: Un estudio florístico ecológico. Tesis de licenciatura. Universidad Nacional Autónoma de México. México. 115 p. 
Mengel, K. y E.A. Kirkby. 1982. Principles of plant nutrition. International Potash Institute, $3^{\underline{a}}$ ed. Berna, Suiza.

Miranda, F. 1958. Estudios acerca de la vegetación. In: E. Beltrán, ed. Los Recursos Naturales del Sureste y su Aprovechamiento, 2. Instituto Nacional de Recursos Naturales Renovables, A.C. México, D.F. p:215-271.

Mizrachi, D., R. Pannier y F. Pannier. 1980. Assessment of salt resistance mechanisms as determinant physioecological parameters of zonal distribution of mangrove species. I. Effect of salinity stress on nitrogen metabolism balance and protein synthesis in the mangrove species Rhizophora mangle and Avicennia nitida. Botanica Marina 23:289-296.

Montes C., C.G.; S. Castillo A. y J. López Portillo. 1999. Distribución del manglar en cuatro sistemas lagunares de la costa de Chiapas, México. Boletín de la Sociedad Botánica de México 64:25-34.

Murren, C.J. y A.M. Ellison. 1998. Seed dispersal characteristics of Brassavola nodosa (Orchidaceae). American Journal of Botany 85: 674-680.

Nash, D.L. y M. Nee. 1984. Verbenaceae. In: A. Gómez P., ed. Flora de Veracruz Instituto Nacional de investigaciones sobre Recursos Bióticos. Xalapa, Veracruz, México 41:11-15.

Nickerson, N.H. y F.R. Thibodeau. 1985. Association between pore water sulfide concentrations and the distribution of mangroves. Biogeochemistry 1:183-192.

Odum, W.E. 1970. Pathways of energy flow in a south in a south Florida estuary. Tesis de doctorado. Universidad de Miami, Coral Gables. 162 p.
Olmsted, I.; A. López O. y R. Durán. 1983. Vegetación de Sian Ka'an: Reporte preliminar. In: Sian Ka'an: Estudios preliminares de una zona en Quintana Roo propuesta como Reserva de la Biósfera. CIQROSEDUE. Cancún, México. p:63-84.

Páez O., F. 2001. The environmental impact of shrimp aquaculture: causes, effects, and mitigating alternatives. Environmental Management 28(1):131-140.

Pool, D.J.; A.E. Lugo y S.C. Snedaker. 1975. Litter production in mangrove forests of southern Florida and Puerto Rico. In: G.E. Walsh; S.C. Snedaker y H.T. Teas, eds. Proceedings of the International Symposium on Biology and Management of Mangroves Vol.1. Universidad de Florida, Gainesville. p:213-237

Pool, D.J.; S.C. Snedaker y A.E. Lugo. 1977. Structure of mangrove forests in Florida, Puerto Rico, México and Costa Rica. Biotropica 9(3):195-212.

Rabinowitz, D. 1975. Planting experiments in mangrove swamps of Panama. In: G.E. Walsh; S.C. Snedaker y H.T. Teas, eds. Proceedings of the International Symposium on Biology and Management of Mangroves Vol.1. Universidad de Florida, Gainesville. p:385-393.

Rabinowitz, D. 1978. Dispersal properties of mangrove propagules. Biotropica 10(1):47-57.

Ramírez, O.M. 1987. Producción de hojarasca y metabolismo estuarino en un ecosistema de manglar en la Laguna de Agua Brava, Nayarit. Tesis de licenciatura. Universidad Nacional Autónoma de México. México. 110 p.

Ramírez G., P. y D. Segura Z. 1994. Ordenación de la vegetación de manglar de la Laguna Panzacola, Chiapas. Los sistemas litorales. 
Universidad Autónoma Metropolitana -Iztapalapa- Universidad Nacional Autónoma de México (2):105-113.

Ramírez G., P.; J. López B. y D. Ocaña. 1998. Mangrove vegetation assessment in the Santiago River Mouth, Mexico, by means of supervised classification using Landsat TM imagery. Forest Ecology and Management 105 (1-3):217-229.

Rico G., V. 1979. El manglar de la Laguna de La Mancha, Ver. Estructura y productividad neta. Tesis de licenciatura. Universidad Nacional Autónoma de México. México. 32 p.

Rico G., V. 1980. Ants and tropical flowers. Biotropica 12(3):223.

Rico G., V. 1982a. Rhizophora harrisonii (Rhizophoraceae), un nuevo registro de las costas de México. Boletín de la Sociedad Botánica de México 41:163-165.

Rico G., V. 1982b. Estudio de la vegetación de la zona costera inundable del noroeste del Estado de Campeche, México: Los Petenes. Biótica 7(2):171-190.

Rico G., V. 1993. Origen y rutas de dispersión de los mangles: una revisión con énfasis en las especies de América. Acta Botánica Mexicana 25:1-13.

Rico G., V. y A. Lot H. 1983. Producción de hojarasca del manglar de la Laguna de la Mancha, Veracruz, México. Biótica 8(3):295-302.

Rico G., V. y M. Palacios R. 1996a. Leaf area variation in Rhizophora mangle L (Rhizophoraceae) along a latitudinal gradient in Mexico. Global Ecology and Biogeography Letters 5(1):30-35.

Rico G, V. y M. Palacios R. 1996b. Salinidad y el nivel de agua como factores en la distribución de la vegetación en la ciénaga del NW de Campeche, México. Acta Botánica Mexicana 34:53-61.

Ruiz L., A. y C.A. Berlanga R. 1999. Modifications in coverage patterns and land use around the HuizacheCaimanero lagoon system, Sinaloa, Mexico: A multi-temporal analysis using LANDSAT images. Estuarine Coastal and Shelf Science 49(1):37-44.

Rzedowski, J. 1978. Vegetación de México. Ed. Limusa, México. 432 p.

Sánchez, M.E. 1963. Datos relativos a los manglares de México. Anales de la Escuela Nacional de Ciencias Biológicas 12:61-72.

Sánchez, R.D. 1994. Comparación estructural de la comunidad de manglar en dos sistemas lagunares costeros del estado de Yucatán, México. Tesis de licenciatura. FMVZUniversidad Autónoma de Yucatán.

Segura Z., D. y P. Ramírez G. 1990. Estructura de los manglares de la Laguna de Panzacola. In: Resúmenes del XI Congreso Mexicano de Botánica. Oaxtepec, Morelos p.128.

SEMARNAT. 1999. Norma Oficial Mexicana de Emergencia NOM-EM001-RECNAT-1999. Diario Oficial, lunes 16 de agosto. Secretaría de Medio Ambiente, Recursos Naturales y Pesca.

SEMARNAT. 2002. Norma Oficial Mexicana NOM-059-ECOL-2001, Protección ambiental - Especies nativas de México de flora y fauna silvestres - Categorías de riesgo y especificaciones para su inclusión, exclusión o cambio - Lista de especies en riesgo. Diario Oficial, miércoles 6 de marzo. Secretaría de Medio Ambiente, Recursos Naturales y Pesca. 
Scholander, P.F.; L. van Dam y S.L. Scholander. 1955. Gas exchange in the roots of mangroves. American Journal of Botany 42:92-98.

Snedaker, S.C. 1989. Overview of ecology of mangroves and information needs for Florida Bay. Bulletin of Marine Science 44(1):341-347.

Snedaker, S.C. y D.J. Pool. 1973. Mangrove forest types and biomass. In: S.C. Snedaker y A.E. Lugo, eds. The role of mangrove ecosystems in the maintenance of environmental quality and a high productivity of desirable fisheries (Contract Report). Center for Aquatic Science, Universidad de Florida, Gainesville. p:C1-C13.

Spalding, M.D.; F. Blasco y C. Field. 1997. World Mangrove Atlas. The International Society for Mangrove Ecosystems. Okinawa, Japón. 178 p.

Teas, H.J. 1979. Silviculture with saline water. In: Hollaender, A.; J.C. Aller; E. Epstein; A.S. Pietro y O.R. Zaborsky, eds. The Biosaline Concept. Plenum Press, Nueva York.

Téllez, O.; E. Cabrera; E. Linares y R. Bye. 1989. Las Plantas de Cozumel. Guía Botánico-Turística de la Isla de Cozumel, Quintana Roo. Instituto de Biología. UNAM México. 52 p.

Thom, B.G. 1967. Mangrove ecology and deltaic geomorphology, Tabasco, Mexico. Journal of Ecology 55:301-347.

Thom, B.G. 1982. Mangrove ecology - a geomorphological perspective. In: B.F. Clough, ed. Mangrove Ecosystems in Australia. Australian National University Press, Canberra. p:3-17.

Toledo, G.; A. Rojas y Y. Bashan. 2001. Monitoring of black mangrove restoration with nursery-reared seedlings on an arid coastal lagoon. Hydrobiologia 444(1-3):101-109.

Tomasini, A.C. 1980. Estudio Palinológico del Oligoceno de Simojovel, Chiapas, México. Tesis de licenciatura. Facultad de Ciencias. Universidad Nacional Autónoma de México. México. 129 p.

Tomlinson, P.B. 1986. The botany of mangroves. Cambridge University Press, Cambridge. 413 p.

Tovilla H., C. 2001. Comunicación personal.

Tovilla H., C. 1994. Mangles. In: De la Lanza E., G. y C. Cáceres M., eds. Lagunas Costeras y el Litoral Mexicano. Universidad de Baja California Sur. p:371-423.

Tovilla H., C.; G.E. De la Lanza y D.E. Orihuela B. 2001. Impact of logging on a mangrove swamp in South Mexico: Cost/benefit analysis. Revista de Biología Tropical 49(2):571-580.

Trejo, J.C.; R. Durán e I. Olmsted.1993. Manglares de la Península de Yucatán. In: S.I. Salazar y N.E. González, eds. Biodiversidad marina y costera de México. Comisión Nacional de Biodiversidad y Centro de Investigaciones Costeras de Quintana Roo, México. p:660-672.

Twilley, R.R. 1985. The exchange of organic carbon in basin mangrove forests in a southwest Florida estuary. Estuarine and Coastal Shelf Science 20:543-557.

Twilley, R.R.; A.E. Lugo y C. Patterson Z. 1986. Litter production and turnover in basin mangrove forests in southwest Florida. Ecology 67(3): 670-683.

Twilley, R.R. y J.W. Day. 1999. The productivity and nutrient cycling of mangrove ecosystem. In: A. Yáñez A. y A.L. Lara D., eds. Ecosistemas 
de manglar en América Tropical. Instituto de Ecología, A.C. México, UICN/ORMA, Costa Rica, NOAA/ NMFS, Silver Spring MD, EUA. p:127-151.

Valiela, I.; L. Koumjian; T. Swain; J.M. Teal y J.E. Hobbie. 1979. Cinnamic acid inhibition of detritus feeding. Nature 280:55-57.

Vázquez Y., C. 1971. La Vegetación de la Laguna de Mandinga, Veracruz. Anales del Instituto de Biología, Universidad Nacional Autónoma de México 42. Serie Botánica (1):49-94.

Vázquez Y., C. 1980a. Notas complementarias a la familia Rhizophoraceae en Veracruz. Biótica 5(1):1-21.

Vázquez Y., C. 1980b. Rhizophoraceae. In: A. Gómez P., ed. Flora de Veracruz. Instituto Nacional de Investigaciones sobre Recursos Bióticos. Xalapa, Veracruz, México 12:1-8.

Vega C., M.E. y F. Arreguín S. 2001. Energy fluxes in a mangrove ecosystem from a coastal lagoon in Yucatan Peninsula, Mexico. Ecological Modelling 137(2-3):119-133.

Villalobos Z., G.J.; A. Yáñez A.; J.W. Day y A.L. Lara D. 1999. Ecología y manejo de los manglares en la Laguna de Términos, Campeche, México. In: A. Yáñez A. y A.L. Lara D., eds. Ecosistemas de manglar en América Tropical. Instituto de
Ecología, A.C. México, UICN/ORMA, Costa Rica, NOAA/NMFS, Silver Spring MD, EUA. p:263-274.

Ward, W.C.; A.E. Weidie y W. Black. 1985. Geology and hidrogeology of the Yucatán and Quaternary Geology of Northeastern Yucatán Peninsula. New Orleans Geological Society. Universidad de Nueva Orleans. Nueva Orleans. 160 p.

Yáñez A., A.; A.L. Lara D.; J.L. Rojas G; D.J. Zárate L.; G.J. Villalobos Z. y P. Sánchez G. 1999. Integrating science and management on coastal marine protected areas in the Southern Gulf of Mexico. Ocean and Coastal Management 42(2-4):319-344.

Yánez E., L.; T. Terrazas y L. López M. 2001. Effects of flooding on wood and bark anatomy of four species in a mangrove forest community. TreesStructure and Function 15(2):91-97.

Zavala, J. 1988. Regionalización natural de la zona petrolera de Tabasco. Casos de Estudio. Instituto Nacional de Investigaciones sobre Recursos Bióticos- División Regional Tabasco Gobierno del Estado de Tabasco. $1^{\underline{a}}$ ed. Villahermosa, Tabasco. 220 p.

Zarur M., A. 1961. Estudio biológico preliminar de la Laguna de Términos (Campeche). Tesis de licenciatura. Universidad Nacional Autónoma de México. México. 112 p. $\diamond$

1 Instituto de Ecología, A.C., Apdo. Postal 63, Xalapa 91000 Veracruz. c.e.: lopez-p@ecologia.edu.mx.

2 Centro de Ecología. UNAM. Apdo. Postal 70-275, México 04510 D.F.

Manuscrito recibido el 20 de febrero de 2002.

Aceptado el 11 de marzo de 2002.

Este documento se debe citar como:

López Portillo, J. y E. Ezcurra. 2002. Los manglares de México: una revisión. Madera y Bosques Número especial:27-51. 


\section{APÉNDICE 1}

Lista de especies de manglar y de las especies asociadas a estas comunidades. Las fuentes son (1) Lot et al., 1975; (2) Rico 1982b; (3) López Portillo 1982; (4) Instituto de Ecología, 1990; (5) Téllez et al., 1989; (6) López Portillo et al., 1989. Las especies marcadas con un asterisco son características del manglar.

\section{Aizoaceae}

Sesuvium portulacastrum L. (3)

Araceae

Anthurium schlechtendalii Kunth. (1)

Alismataceae

Sagittaria lancifolia Linnaeus L. (1)

Anacardiaceae

Metopium brownei (Jacq.) Urb. (4)

Annonaceae

Annona glabra L. $(1,5)$

\section{Apocynaceae}

Echites yucatanensis Millsp. ex Standl.

(5)

Rhabdadenia biflora (Jacq.) Muell. Arg.

$(1,3,5)$

\section{Avicenniaceae}

* Avicennia germinans L.

Bombacaceae

Pachira aquatica Aubl. (1)

\section{Bromeliaceae}

Aechmea bracteata (Sw.) Mez. $(1,2,5)$

Bromelia pinguin L. (1)

Tillandsia dasyliriifolia Baker (1)

Tillandsia leiboldiana Schlecht. (1)

Tillandsia schiediana Steud. (1)

Tillandsia strobilifera Ed. Morr. (1)

\section{Cactaceae}

Selenicereus testudo (Karw.) Buxbaum $(3,5)$

\section{Combretaceae}

* Laguncularia racemosa (L.) Gaertn.
Conocarpus erectus L.

Conocarpus erectus var. sericeus

Grisebach (4)

Convolvulaceae

Ipomoea sp. (1)

Compositae

Borrichia frutescens (L.) DC. (3)

Cyperaceae

Cladium jamaicense Crantz $(4,6)$

Cyperus ligularis L. (1)

Fimbristilis spadicea (L.) Vahl. (1)

\section{Chenopodiaceae}

Salicornia bigelovii Torr. (3)

Salicornia perennis Mill. (1)

Suaeda linearis Ell. (1)

\section{Gramineae}

Distichlis spicata (L.) Greene $(1,3)$

Spartina spartinae (Trin.) Merr.

Guttiferae

Clusia sp. 1

Clusia sp. 2 (1)

Leguminosae

Andira galeottiana Standl. (1)

Acacia cornigera (L.) Willd. (1)

Dalbergia brownii L. (1)

Dalbergia ecastophilla L. (1)

Inga sp. (1) (posiblemente vera)

Machaerium lunatum (L.F.) Ducke (1)

Pithecellobium lanceolatum ( $\mathrm{H}$. et B.)

Benth. (3)

Lonchocarpus luteomaculatus Pitt. (1)

\section{Loranthaceae}

Struthanthus cassythoides Millsp. ex

Standl. (1)

Malvaceae

Malvaviscus arboreus Cav. (3)

Hibiscus tiliaceus L. (1)

Melastomataceae

Mouriria aff. muelleri Cogn. (1)

\section{Moraceae}

Ficus insipida Willd. (1) 


\section{Orchidaceae}

Encyclia cochleata (L.) Lemee. (1)

Epidendrum alatum Batem. (1)

Epidendrum ciliare L. (1)

Epidendrum nocturnum Jacq. (1)

Epidendrum pygmaeum Hook. (1)

* Brassavola nodosa (L.) Lindl. (4,5)

Myrmecophila tibicinis (Bateman) Rolfe $(4,5)$

\section{Palmae}

Acoelorraphe wrightii (Griseb. and $\mathrm{H}$. Wendland) $\mathrm{H}$. Wendland ex Beccari

\section{Piperaceae}

Peperomia obtusifolia A. Dietr. (1)

\section{Pontederiaceae}

Pontederia sagittata C. Presl. (1)

\section{Polypodiaceae}

* Achrostichum aureum L. $(1,3)$

* Achrostichum danaeaefolium L. Elaphoglossum sp. (3)

\section{Rhizophoraceae}

* Rhizophora mangle L.

* Rhizophora harrisonii Leechm.
Rubiaceae

Hillia tetrandra Sw. (1)

Randia aculeata L. (1)

Sapindaceae

Paullinia pinnata L. (1)

Sapotaceae

Manilkara zapota L. van Royen $(4,5)$

Scrophulariaceae

Vriesea pectinata LB Smith (1)

Solanaceae

Lycium carolinianum Walt. (3)

Theaceae

Ternstroemia tepezapote Schlecht. and Cham. (1)

Typhaceae

Typha domingensis Pars. (1)

Verbenaceae

Clerodendron ligustrinum (Jacq.) E. Br. D.

(1) 
Esta página fue dejada en blanco intencionalmente. 